\title{
An Analysis of Franz Image from the Perspective of Artistic Aesthetics
}

\author{
Chunmeng Weng \\ School of Art and Design \\ Wuhan University of Science and Technology \\ Wuhan, China 430065
}

\author{
Yangyu Chen \\ School of Art and Design \\ Wuhan University of Science and Technology \\ Wuhan, China 430065
}

\begin{abstract}
In ancient Chinese civilization, china is undoubtedly indispensable treasure. In 2001, the Chinese porcelain brand of "Franz" began to display its talent in the international stage. And then, Franz was quickly displayed in the showcases of world's major boutique. In the past century, the international market had been dominated by Europe, Japan porcelain. With the emergence of Franz, it changed the status quo. In this paper, the author puts forward four levels with the beauty of Franz images: artistic carrier, artistic language, artistic image and artistic connotation. And this paper is supported by the theory of artistic hierarchy in art aesthetics. It has made deep analysis of the artistic beauty of Franz for the audience to better understand the brand image of Franz. At the same time, the scholars can rich and develop the theory of art hierarchy through the analysis of the art works of Franz.
\end{abstract}

Keywords-artistic aesthetics; Franz; art hierarchy; analysis of image

\section{INTRODUCTION}

China has a profound historical civilization and aesthetic background. As an important Chinese patented invention, china has been the messenger to spread the Chinese culture. In the worldwide, the foreign countries have fascinated and imitated Chinese porcelain. In this process, the beauty of the life, artistic beauty, scientific beauty and other aesthetic ideas of the Chinese porcelain are quietly spread all over the world. 1From the perspective of art, compared to Chinese painting and calligraphy, world recognition and collection value of china is higher. For nearly a hundred years, Europe and Japan porcelain have taken the lead of the international highend ceramic brands. And the status quo hasn't been changed. It can be said that the emergence of Franz create new era of Chinese porcelain. It has changed dull and static images of the traditional porcelain. And now, the porcelain is art works with aesthetic conception and humanistic feelings.

Yang Liping. "The spread of porcelain and Chinese traditional aesthetics" [J], "Fujian Forum-Humanities and Social Science Edition", 2016(4), p127.

\section{A BRIEF INTRODUCTION TO THE ARTISTIC HIERARCHY FROM THE PERSPECTIVE OF ART AESTHETICS}

\section{A. The Theoretical Basis}

As early as the beginning of the 20th century, the famous Polish philosopher and anesthetist, Roman Ingarden ${ }^{2}$ (18931970) put forward the unique hierarchical theory of literary and artistic works for the literary works. This theoretical achievement is the pioneering contribution to the study of artistic aesthetics. And it has become the basic framework for the further study of the hierarchical structure of art. Roman Ingarden argued that literary and artistic works are not real and ideal objects. They are "intentional objects". From the perspective of artistic aesthetics, literary and artistic works are divided into four closely related levels: phonological creation, meaning creation, the reproduction of the object and schema view. 3Roman Ingarden didn't make research on the art works. However, to some extent, there is similarity between literary and artistic works and art works. In "The Principles of Art", Zhang Qian has made adjustment and innovation of Roman Ingarden's four levels, and he has also changed the objects of study from literary and artistic works to art works. He has divided the art hierarchy into: material carrier, form symbol, image world and ultimate sense. All of the levels are interrelated and interlocking. As the art works, they must meet the requirements in first three levels. In other words, they can be called art works which meet the requirements in first three levels. For the layer ultimate sense, it may come by something with luck but not by searching for it. And it is also the most attractive level of art works.

\section{B. The Artistic Hierarchy Theory}

Based on the research results of the above-mentioned experts of structural theory, the author takes the brand of Franz as the research object, and carries out the targeted analysis of art hierarchy with the purpose. Combined with the material, shape, artistic conception and other terms of

Roman Ingarden, Polish full name is Roman Witold Ingarden. And it also can be translated as "Ingarden", "Incarden" or "Infingdon" and so on. According to the translation of "Art Principle" by Zhang Qian, this article uses "Ingarden" uniformly.

Roman Ingarden. "Literary Works" [M], Zhang Zhenhui translation, Kaifeng: Henan University Press, 2008, p49. 
Franz, he has put forward four levels: art carrier, artistic language, artistic image and artistic connotation.

The art carrier refers to the material that is required for the creation of art works. Art works exist in time and space with the material carrier. And then, the art works have unique image characteristics. Such as the art carrier of traditional Chinese painting: ink, rice paper. The art carrier of Wood carving: wood, burin. The art carrier of the dance drama is the dancing posture of the dancer, the stage and the light. Art language refers to specific expression of the art works. And then, it has formed its own unique artistic language. We can directly feel the art language of art works. And the art language is also the easiest to be observed. Such as wet and dry, intensity, black and white of ink of traditional Chinese paintings; the level and oblique tones, antithesis, parallelism, rhyme of literary and artistic works; the different art types of artistic language are different. As the core level, art image is built on the emotional levels of the artistic carrier and the artistic language. Artistic image is the real aesthetic object. The physical entities that we can see aren't the ultimate aesthetic objects. The so-called aesthetic objects are transformed through the observation and sentiment of art works. They are the image world with subjective sense. It can be said that the art image created through the viewers' imagination. The art isn't an objective existence. Therefore, there is reunification in the aesthetic appreciation of artistic image: the unity of subjective and objective factors; the unity of forms; the unity of personality and commonality. The artistic connotation is the ultimate level that the art work is derived from the aesthetic meaning of the carrier, the language and the image, which requires people to use the mind to understand and explore the art. "The connotation is always something more profound than the images directly appearing. It is an inherent vitality, emotional soul, strength and spirit manifested by the image. That is what we call the connotation of the art works. ${ }^{4}$ This is Hegel's understanding of the meaning of the word.

\section{ANALYSIS ON THE IMAGE OF FRANZ -} INTERPRETATION OF THE HIERARCHY OF THE ART WORKS

\section{A. Art Carrier - Depending on the High-quality Clay}

Franz uses high-quality and meticulous porcelain clay, which is also known as kaolin. It is named after the village of Kaolin of a porcelain city of China, Jingdezhen. It is a white or off-white shiny soft mineral. And it is used as porcelain material of Franz with its characteristics of white and bright, high fire resistance, high precision, high plasticity and high viscosity. At the same time, Franz has exclusive formula. With the underglaze technology, Franz products are moist and transparent. The color is crystal, and it wouldn't fade over time.

And the art carrier isn't the reality of Franz. And it is difficult for us to understand the artistic beauty of Franz. However, in terms of porcelain clay, it is the material basis

\footnotetext{
4 [German] Hegel (G.W.F.). "Aesthetics" (first volume) [M], "Zhu
} Guangqian Complete Works" (Volume 13), Anhui Education Press, 1990 edition, p23-p24. of Franz. It can be said that there is no Franz without porcelain clay. And Franz is attached to porcelain clay. Therefore, the art carrier is the earliest art level we can understand.

\section{B. Artistic Language - The Three-dimensional Presentation of Natural Beauty}

Franz makes good use of natural flora and fauna, and they are used as art elements to present the art works with three-dimensional vivid exquisite styles as unique art practices. These two points are the unique art language of Franz.

"Fig. 1" The artistic languages of the four Franz are lilies, bamboo and birds, waves and dolphins, and butterflies. From the following four products, people can observe that these design elements are taken from the unrestrained nature of the wild, flowers and insects. And these elements are presented in the art works with three-dimensional modeling. ${ }^{5}$ It uses new artistic flowing western lines to shape the porcelain vase. Also, it has integrated the eastern elegant humanistic temperament into the porcelain vase. And then, it breaks the inherent unattainable, rigid image of the traditional porcelains. The porcelain exudes intimate feelings touched the deepest nerve in our hearts. It seems that we can enter the inner spiritual world of porcelain and listen to the most original and purest life movement of nature.

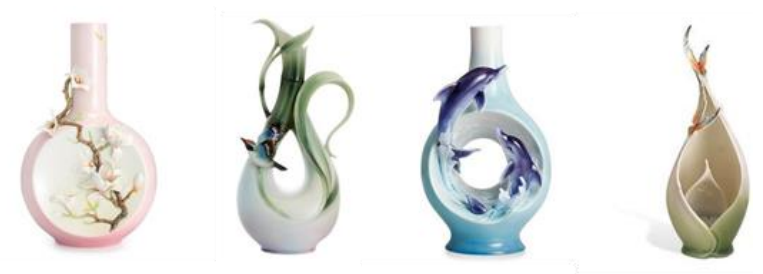

Fig. 1. Franz products.

a. It is from official website of Franz: http://eshop.franzcollection.com.tw/cn/collection_limit

\section{Artistic Image - from the Concretization to the Abstract} of the Scene World

Through the tactile and visual presentation of the carrier and the image, the appreciator begins to perceive the abstract imaginary world from figurative works of art, enabling the mind and body to enter a certain scene of the art works. In the following "Fig. 2", it takes the porcelain of "no wind for long day" as a specific case to explain the art image of Franz. "No wind for long day" is the limited edition porcelain among the series "poetic life of Wu Guanzhong". And it was formally launched by Franz in November, 2011. Porcelain bottles take the body of bottle as canvas. It has presented $\mathrm{Wu}$ Guanzhong's ink paintings with special carving skills and color of Franz. And the three-dimensional sculpture has become eternal porcelain. From the art works, we can imagine that two smart birds quietly nestle against each other on the branches of bleak woods. The grove is quiet. And everything is so fresh. People would forget the hustle and bustle of the city. And they just want to immerse themselves

\footnotetext{
5 Yiyu. "Proud Franz" [J], "Chinese Hand", 2007(3), p28.
} 
in this paradise-like fairyland to enjoy the peace and quiet. This kind of perceptual imagination is the image world of the appreciator brought by the art work. The image world of the art work is the true aesthetic object as well as the core value of the art work. At the same time, this image world is also a mark to judge whether the art work is established or not.
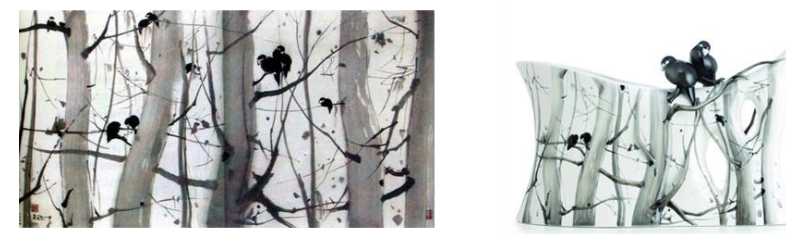

Fig. 2. "No wind for long day" paintings and porcelain.

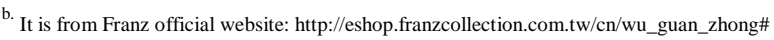

\section{Artistic Connotation - Comprehend the Humanistic Connotation with Natural Care}

The artistic connotation refers that art works may come by something with luck but not by searching for it. And it needs the appreciator's intention to comprehend and explore the realm. The concept can't express the art works. The connotation is an important reason for the immortal soul of art works. Chen Liheng, the founder of the brand hopes that Franz can become the transmitter of the charm of nature and the inheritor of oriental philosophy. We hope that people can attain the essence of oriental philosophy of "beauty of everything, and free heart of benevolent people" through Franz. People learn the aesthetic essence of nature, and understand the truth of "celestial voices, gentleman renewing strengths". And then, they can improve the grade. In "Fig. 3", it is the classic "freehand life" series of Franz. It presents minimalist and introverted style with oriental deep meditation. Pitta brachyura shuttles in the bamboo. Fictitious and realistic comparison brings us into green bamboo fairyland. Through this group of venerable porcelain, we can understand the humanistic connotation of ecological care. Pitta brachyura are listed as the endangered species of Taiwan's national treasure bird. We should cherish every life on earth and create a beautiful world. And people would have another comprehension. People would reverence tenacious vitality of bamboo. No bending of the sticks tells that people should temper force with grace, adhere to selfpreservation of the heart, and pursue the ideal of mind.
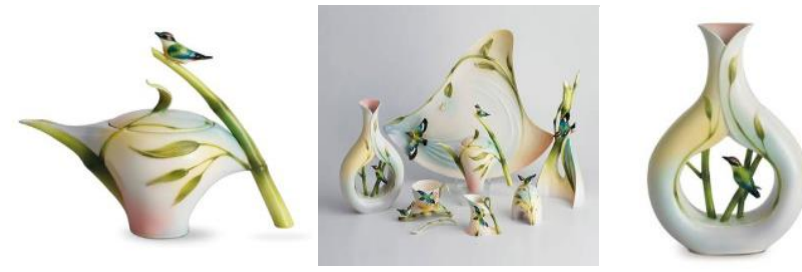

Fig. 3. The series of "Freehand life".

c. It is from Franz official website: http://eshop.franzcollection.com.tw/cn/bsongbird\#

From the perspective of art aesthetics, it analyzes four levels of Franz with art hierarchy from the outside to the inside. These four levels closely related form an organic entity. Each subsequent layer is always built on the basis of the previous layer, permeating into both the former and the latter. Franz has four progressive layers of art. Franz became the focus of world attention. Nowadays, it has gradually become porcelain art work that can be called internationally in the international market. It is widely recognized in the highly competitive gift market overseas. In the oriental market, porcelain has repeatedly been chosen as the national ceremony. In 2009, "Splendid Nylon" was presented to President Barack Obama. In 2011, "Everlasting Excellence" was presented to Russian Prime Minister Putin. In 2012, "Hibiscus Jasper" was presented to German Chancellor Moore.

\section{CONCLUSION}

In summary, based on the theoretical basis of scholars, this article takes Franz as specific research object, and divides the hierarchy of art works into art carrier, art language, artistic image and artistic meaning. From the perspective of artistic aesthetics, this article makes an indepth analysis of the artistic works of Franz. From the external visual image to the inner humanistic spirit, Franz firmly roots in the soil of national culture and regained its new life. In today's market, there are a large number of dailyuse ceramic brands and endless stream of technologies and new materials. We must shape our unique brand image if we want to stand out among many porcelain brands. The products of Franz make oriental people feel that it is very oriental, and the products of Franz make westerners think it is very western. The oriental people see that "everything is in one". The westerners are shocked by the charm of nature. ${ }^{6}$ The successful case of Franz provides a new way of thinking and direction for the development of domestic porcelain brand. In the gradual integration of the world today, it is necessary to find a point for the fusion of Chinese and Western cultures based on the international market. It requires that we can't forget or obey the old ways, and we should achieve national and international reunification and the unification of tradition and modernity. And then, the "visible" porcelain can convey "invisible" national culture.

\section{REFERENCES}

[1] Zhang Qian. "Art Principle" [M]. Beijing: Peking University Press, 2008.

[2] Wu Xiumei. "The nationality and contemporaneity of design - Taking the Franz as an example" [J], "Hundred Schools in Arts", 2015 (06).

[3] Xu Chen, Wang Aihong. "Study on Jingdezhen ceramic culture and brand awareness of creative industries-Taking Franz as an example" [J], 2013 (06).

[4] Liang Ruili. "Franz: To be respectable brand" [J], "Oriental Culture", 2010 (17).

[5] Ma Yuling: "New trend of porcelain capital—Practice and thinking on the development of ceramic culture industry of Jingdezhen" [J] "Seeking", 2009 (23).

[6] Huang Qiuli. "Creative Franz" [J], "Chinese entrepreneurs", 2009 (01).

6 Wang Wenjuan. "Beauty of everything, and free heart of benevolent people - Interview with the CEO of Haichang Ceramic Industry of Franz Chen Liheng" [J] ", "ZOL", 2011(4), p137. 